\title{
The attitudes of primary care providers towards screening for colorectal cancer
}

\author{
Jesús López-Torres-Hidalgo ${ }^{1}$, María José Simarro-Herráez², Joseba Rabanales-Sotos³, \\ Ramona Campos-Rosa ${ }^{4}$, Belén de-la-Ossa-Sendra ${ }^{5}$ and Carmen Carrasco-Ortiz ${ }^{2}$
}

${ }^{1}$ Centro de Salud Universitario Zona 4. Albacete. Facultad de Medicina. Albacete, Spain. ${ }^{2}$ Centro de Salud de Villarrobledo. Villarrobledo, Albacete. Spain. ${ }^{3}$ Unidad de Investigación. Gerencia de Atención Primaria. Albacete, Spain. ${ }^{4}$ Servicio de Farmacia. Gerencia de Atención Primaria. Albacete, Spain. ${ }^{5}$ Centro de Salud de Almansa. Almansa, Albacete. Spain

\begin{abstract}
Background and objective: the scientific community supports the appropriateness of colorectal cancer screening, and there is consensus on the need to raise awareness about the significance of prevention among both health care professionals and the population. The goal was to record the attitude of primary care providers towards colorectal cancer screening, as well as the main barriers to both patient and provider participation.

Methods: a cross-sectional, observational study was performed of 511 professionals in Albacete Health District. Variables included views on screening effectiveness and cost-effectiveness, acceptance by providers and patients, barriers to participation, frequency of prevention recommendations, and education needs.

Results: most (76\%) considered screening was effective; $85 \%$ said acceptance of fecal occult blood testing was intermediate or high, and $68.2 \%$ this is also the case for colonoscopy when needed; $71.9 \%$ would recommend screening should a population-based program be implemented (currently only $9.7 \%$ recommends this). Correspondence analysis revealed that recommendation is more common when assigned populations are smaller.

Conclusions: most providers consider screening is both effective and acceptable for patients. In today's situation, where screening is only performed in an opportunistic manner, the proportion of professionals who commonly recommend screening for the mid-risk population is low, especially when assigned populations are huge.
\end{abstract}

Key words: Colorectal cancer. Screening. Primary care.

López-Torres-Hidalgo J, Simarro-Herráez MJ, Rabanales-Sotos J, Campos-Rosa R, De-la-Ossa-Sendra B, Carrasco-Ortiz C. The attitudes of primary care providers towards screening for colorectal cancer. Rev Esp Enferm Dig 2013;105:272-278.

Received: $11-02-2013$

Accepted: 27-05-2013

Correspondence: Jesús López-Torres Hidalgo. Centro de Salud Zona 4. C/ Seminario n. ${ }^{\circ}$ 4. 02006 Albacete, Spain

e-mail: jesusl@sescam.org

\section{INTRODUCTION}

The cancer strategy of Spain's Sistema Nacional de Salud (1), approved by Consejo Interterritorial in 2009, suggests that colorectal cancer (CRC) should be screened in the 50 to 69 -year-old population every two years using fecal occult blood (FOB) testing. This strategy also considers a gradual implementation and sets a coverage goal of $50 \%$ for 2015 (2). This is a disease susceptible to screening (3) as it represents a huge health care issue for which tests exist that allow detection in the early stages, when therapy is most effective. Hence, the scientific community supports the adequacy of CRC screening, whose benefit-risk ratio is favorable (3), and there is wide consensus on the need to raise awareness among the population, health care providers, and regulatory agencies regarding the importance of prevention for this condition (4). Both the European Union and the US Preventive Services Task Force and Canadian Task Force on Preventive Health Care have recommended population-based CRC screening for years (5).

As with many other preventive activities, primary care providers play a key role in the spreading of primary prevention measures for CRC by suggesting screening to the mid-risk population, identifying high-risk individuals through proper history taking, and sharing the management and follow-up of subjects with specific colorectal lesions with specialist care professionals (6). However, participation in these programs is low, in fact lower than in other cancer prevention programs. The reasons for such low participation include the perception that the ensuing exams will be uncomfortable and painful, and lack of awareness regarding the importance of prevention programs for this condition among the population and also some health care providers (4).

Health professionals should be familiar with the various screening options available, and recommend these options to those who may benefit from them. While there is no screening strategy in most Spanish autonomous communi- 
ties, including Castile-La Mancha, any initiative in this regard is surely better than no screening at all. Even though the community perspective is stagnant, the resolve of some providers, agencies and foundations does seem to be successful and is becoming translated into the development of screening initiatives based on FOB detection (2).

The goal of this study is to gain insight into the attitudes of health care providers towards CRC screening, as well as the main barriers to both patient and professional participation.

\section{MATERIAL AND METHODS}

This is an observational, cross-sectional study of primary care providers that includes 511 professionals (family physicians and nurses) working at sites within Albacete Health District, which covers a total population of 399,191 inhabitants and 36 basic health care areas. Sample size represents a confidence level of $95 \%$, an accuracy of $\pm 5 \%$, and unknown expected frequency of favorable attitudes towards screening $(p=0.5)$, and an increase of $33 \%$ to compensate for foreseeable non-responses.

After suggesting participation, providers were invited to fill out a self-administered $a d-h o c$ questionnaire with 23 multiple-choice, estimation questions regarding CRC screening, as well as 7 multiple-choice closed questions about the personal and professional characteristics of study subjects. To ensure the validity of questionnaire contents a review of all previously reported theoretical contributions was undertaken prior to its development (7-17). Questions, which were decided upon by consensus among investigators, were written down in accordance with the principles of brevity, succinctness, simplicity, and neutrality. The development of an adhoc questionnaire was selected on acknowledging the diversity of previously used questionnaires, their information on the research topic being complementary.

A pilot administration to 10 health care providers was carried out to assess comprehension and the distribution of questions within the questionnaire, as well as the time needed to complete it, which was around 10 minutes. Following opportune corrections a definitive questionnaire was developed (Appendix), whose acceptable internal consistency was verified (Cronbach's alpha: $80.1 \%$ ). As regards field work, the medical or nurse coordinator in each health center to request their cooperation in the distribution and subsequent collection of questionnaires. Regarding health centers from which no response was obtained after 1 month, the researchers personally contacted these providers to request that questionnaires be completed. Data were collected from January to June, 2012. Anonymity and confidentiality for the information provided were warranted to respondents, as well as a limited use of data exclusively for the purpose of the suggested research. The study was approved by Albacete Health District Ethics Committee.

Studied variables included: providers' views on the effectiveness and cost-effectiveness of screening, acceptance by both professionals and patients, intended participation should a population-based program become implemented, significance of involvement by family doctors and nurses, barriers to both patient and professional participation using a scale with a score of 0 to 5, frequency of preventive recommendation in the present situation, need for specific training, and personal (age, gender) and professional (profession, rural or urban status, professional experience, work load, and assigned population).

Participant responses were introduced in a database for subsequent debugging and analysis. Statistical analyses of data were performed using the IBM SPSS Statistics 19 software package. Participant characteristics were first described, and frequency distribution, $95 \%$ confidence intervals, and measures of central tendency and dispersion were estimated. Then primary variable independence was ascertained using the chi-square verisimilitude ratio test, with significance at 0.05 . The association between screening recommendation frequency by providers and profession, assigned population, age, rural or urban setting, and professional experience variables was tested using logistic regression. Finally, a bidimensional analysis of correspondences was used to represent a potential association between FOBT screening recommendation frequency and population assigned to each individual provider within coordinates.

\section{RESULTS}

From a total of 511 family doctors and nurses 321 $(62.8 \%)$ responded in 32 of all 36 health centers in Albacete Health District (health centers from which no response was received were all in the rural setting and had a low number of professionals). The 159 family doctors who responded, most of them males ( $57.2 \%$ ), had a mean age of 48.7 years (SD: 8.4) and a mean work experience of 19.6 years (SD: 9.1). In turn, all 162 nurses who responded, most of them females $(71.6 \%)$, had a mean age of 46.0 years (SD: 10.0$)$ and a mean work experience of 17.3 years (SD: 9.9). Their personal and professional characteristics (159 family doctors and 162 nurses), are listed in table I.

Most respondents (76.0\%; $95 \%$ CI: 71.2-80.8) considered that CRC screening using FOBT was very effective or quite effective, and approximately one half $(52.0 \%$; $95 \%$ CI: 46.4-57.6) thought cost-effectiveness was high or moderate. In all, $85 \%$ of respondents considered that patient acceptance for this test is intermediate or high, and $68.2 \%$ believed also colonoscopy was well accepted when FOB is detected. Most of them (71.9\%; $95 \%$ CI: 66.8-77.0) would recommend FOBT screening, followed by colonoscopy when appropriate, to people older than 50 years should a population-wide screening program become implemented ( $24.4 \%$ would only recommend it to some patients over 50 years of age, $1.3 \%$ would not recommend it, and $2.5 \%$ did not know). Participation of subjects older than 50 in the program would be high according to $33.8 \%$ of respondents, intermediate according to $49.4 \%$, and low according to 
Table I. Personal and professional characteristics of participating family doctors and nurses

\begin{tabular}{|c|c|c|c|c|}
\hline Characteristics & Family physicians No. (\%) & Nurses No. (\%) & Total No. (\%) & $p$ \\
\hline \multicolumn{5}{|l|}{ Sex: } \\
\hline Males & $91(57.2)$ & $46(28.4)$ & $137(42.7)$ & $<0.001$ \\
\hline \multicolumn{5}{|l|}{ Age: } \\
\hline 50 years or younger & $71(44.6)$ & $93(57.4)$ & $164(51.1)$ & \multirow[t]{2}{*}{0.01} \\
\hline Over 50 years & $82(51.6)$ & $59(36.4)$ & $141(43.9)$ & \\
\hline \multicolumn{5}{|l|}{ Professional experience: } \\
\hline 20 years or lower & $67(42.1)$ & $78(48.1)$ & $145(45.2)$ & \multirow[t]{3}{*}{ NS } \\
\hline Over 20 years & $75(47.2)$ & $62(38.3)$ & $137(42.7)$ & \\
\hline No answer & $17(10.7)$ & $22(13.6)$ & $39(12.1)$ & \\
\hline \multicolumn{5}{|l|}{ Workplace: } \\
\hline Population lower than 10,000 & $63(39.6)$ & $63(38.9)$ & $126(39.3)$ & NS \\
\hline Over 35 patients/day & $108(67.9)$ & $33(20.4)$ & $141(43.9)$ & $<0.001$ \\
\hline \multicolumn{5}{|l|}{ No. of assigned patients: } \\
\hline Fewer than 1500 & $59(37.1)$ & $63(38.9)$ & $122(38.0)$ & \multirow[t]{2}{*}{ NS } \\
\hline Over 1500 & $100(62.9)$ & $99(61.1)$ & $199(62.0)$ & \\
\hline
\end{tabular}

NS: Not statistically significant.

$12.8 \%$. For $98.8 \%$ of cases family doctors' involvement in proper program implementation would be very important or quite important, and for $97.8 \%$ nurses' involvement would also be very significant or quite significant.

Table II shows -by score obtained- the potential barriers to participation in a CRC screening program by the population and health care providers. Presently only $9.7 \%(95 \%$ CI: 6.3-13.0) of professionals usually recommend FOBT to asymptomatic patients older than 50 years of age, $57.6 \%$ do so occasionally, and $32.7 \%$ never suggest screening. The need for updated education on CRC screening was only acknowledged by $87.9 \%$ (95 \% CI: 84.1-91.6) of providers.

A greater percentage of medical professionals considered that screening cost-effectiveness was high as compared to nurses $(19.5 \%$ versus $6.2 \% ; p<0.001)$, and a greater percentage usually recommend it to patients over 50 too $(13.2 \%$ versus $6.2 \% ; p=0.03)$. In turn, nurses more commonly acknowledge their need for extended education regarding CRC screening (97.5\% versus $78.0 \%$; $p<0.001$ ).

Using logistic regression the proportion of providers who recommend screening (usually or sometimes) was seen to be higher among doctors (OR: 6.6; $95 \%$ CI: 3.7-11.9) and among those with fewer than 1,500 patients assigned (OR: 1.8; $95 \%$ CI: 1.1-3.2), with no association with variables such as age, professional experience, and rural or urban setting.

The results of a correspondence analysis between frequency of screening recommendation by providers and number of assigned patients showed a statistically significant association (Chi-squared: 43.297; $p<0.001$ ), which demonstrated that these two variables are not independent. Figure 1 shows a graphic representation of this correspondence analysis wherein a shorter distance may be seen between occasional FOBT orders by providers and an assigned population of 1,500 to 2,000 inhabitants, between usual FOBT orders and an assigned population below 1,500 , and between no FOBT orders and a population above 2,000.

\section{DISCUSSION}

Results allowed to acknowledge that most primary care providers consider CRC screening effective and FOBT acceptable by the population. Most would also recommend screening should a population-wide program become implemented. Under present circumstances, the frequency wherewith providers recommend this preventive activity to patients is very low, being higher by family doctors and those with lower assigned population volumes.

The obtained response rate is acceptable and similar to that of a previous study in Catalonia and Balearic Islands (7), in both cases higher than in studies from other countries $(8,11,12,14,15)$. Despite this, a relevant proportion of providers refused to participate, and these might be subjects with a less favorable attitude towards screening. Even though providers from various health centers participated, 
Table II. The significance of potential barriers for the population and health care providers to take part in a screening program for CRC

\begin{tabular}{|c|c|c|c|c|}
\hline Potential barriers & $F P$ & $N$ & Total & $p$ \\
\hline \multicolumn{5}{|c|}{ For the population to participate in a screening program for CRC } \\
\hline Fear of colonoscopy & $3.8(1.0)$ & $4.0(1.0)$ & $3.9(1.0)$ & NS \\
\hline Fear of CRC identification & $3.4(1.1)$ & $3.8(1.1)$ & $3.6(1.2)$ & 0.002 \\
\hline Lack of knowledge on CRC & $3.3(1.0)$ & $3.7(1.1)$ & $3.5(1.1)$ & 0.005 \\
\hline Displeasure with stool sample handling & $2.2(1.3)$ & $2.3(1.4)$ & $2.3(1.3)$ & NS \\
\hline No perceived benefits from the program & $2.3(1.1)$ & $2.3(1.3)$ & $2.3(1.2)$ & NS \\
\hline
\end{tabular}

For health care providers to participate in a screening program for CRC

\begin{tabular}{|c|c|c|c|c|}
\hline Providers' lack of time & $3.1(1.5)$ & $3.2(1.5)$ & $3.2(1.5)$ & NS \\
\hline Anxiety problems in patients from false positive FOBT results & $2.9(1.2)$ & $3.1(1.4)$ & $3.0(1.3)$ & NS \\
\hline Lack of resources for screening implementation & $2.9(1.5)$ & $2.8(1.6)$ & $2.9(1.5)$ & NS \\
\hline False feelings of safety from potential false negative FOBT results & $2.8(1.2)$ & $2.8(1.2)$ & $2.8(1.2)$ & NS \\
\hline The procedure's invasive nature should colonoscopy be required & $2.5(1.5)$ & $2.8(1.5)$ & $2.7(1.5)$ & NS \\
\hline Difficulty to discuss screening procedures with patients & $2.5(1.5)$ & $2.4(1.4)$ & $2.4(1.4)$ & NS \\
\hline Lack of knowledge of providers on screening programs & $2.1(1.4)$ & $2.5(1.5)$ & $2.3(1.4)$ & 0.04 \\
\hline Lack of knowledge of providers on CRC & $1.8(1.3)$ & $2.2(1.3)$ & $2.0(1.4)$ & 0.003 \\
\hline
\end{tabular}

Scores are mean (SD) values on a 0 (not significant at all) to 5 (highly significant) points scale. CRC: Colorectal cancer. FOB: Fecal occult blood. FP: Family physicians. N: Nurses. NS: Not statistically significant.

a generalization of results to other health districts with a higher experience in CRC screening could be limited.

In the opinion of most providers colonoscopy would be acceptable for patients in the presence of positive FOBT results should a population-based program become implemented. In fact, according to pilot studies performed in our country, colonoscopy is accepted by $89 \%$ of subjects with

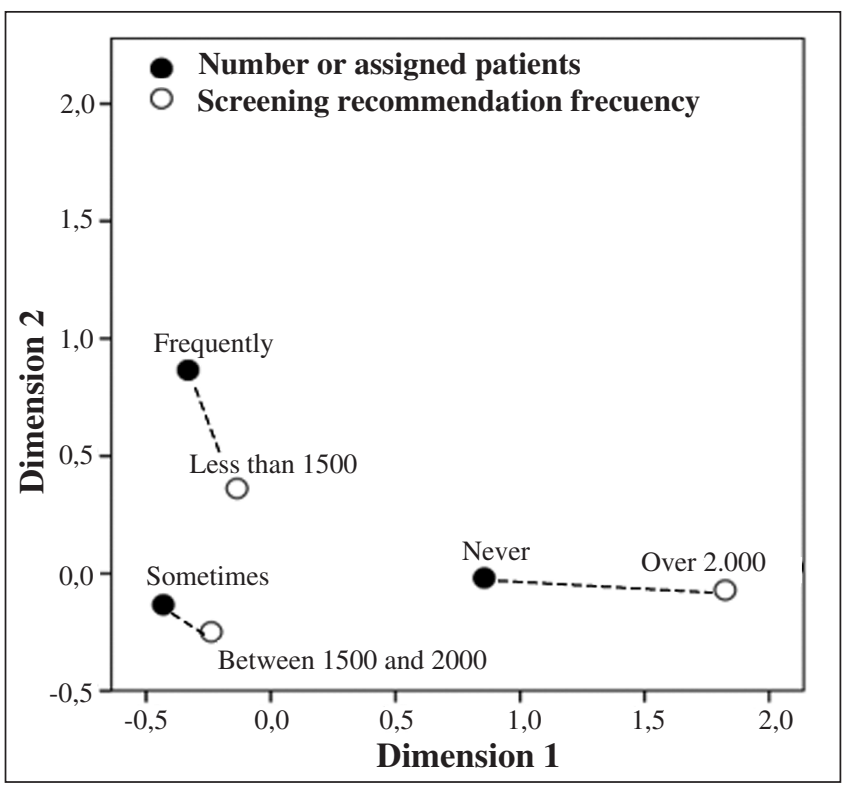

Fig. 1. Plot analysis of correspondences between screening recommendation frequency by providers and number of assigned patients. positive testing (18). However, as regards the potential involvement of the population, a key barrier identified would be fear of needing a colonoscopy procedure or of diagnosis with CRC. Similarly, fear of colonoscopy represents the primary reason for resistance to participation in other Spanish regions (7). Presently, participation in communities where screening is performed is $35-50 \%$ (19), hence clearly improvable, and inconsistencies may exist between expectations and obtained results. In this regard, further education for these providers could be beneficial. According to our results and other previous studies (15) there are many who consider further training on CRC screening a necessity.

In the present situation, where CRC secondary prevention is only opportunistically performed in Castile-La Mancha, the proportion of professionals who usually recommend screening for the mid-risk population remains very low, considerably lower as compared to other countries $(8,12,13)$. This is particularly so when numbers assigned to providers are higher and the fact, while not seen in a previous study (9), is probably related to higher workloads and less time available for preventive measures. Family physicians have already highlighted lack of time (7) as the primary barrier to becoming involved in screening. As in prior studies $(8,11)$, other variables, including sociodemographic characteristics, have shown no association with the frequency with which providers claim to carry out such preventive activity.

Some aspects are key for successful screening, including the involvement of a high percentage of the population; 
however, the individuals who most often refuse to participate are precisely those with a higher risk for disease (20). This is why primary care providers, in a privileged position to inform and counsel patients, may play a key role in the development of this preventive activity (11). Although negative attitudes towards FOBT by some providers have been reported (8) and studies suggest their beliefs and practices are highly variable (11), in our results and those from other previous studies (7) most professionals expound a highly favorable view of screening and seem ready to recommend it to patients. Their attitude towards screening has been seen to be a relevant determinant of involvement (11), and a common reason to refuse participation is the absence of recommendation by a physician (13), which represents the strongest predictor of patient acceptance $(16,21)$.

To this day, screening recommendation has been associated with perceived efficacy by providers (15), who would consider it inferior to that of other screening measures, including screening for breast and cervical cancer, despite comparable evidence regarding effectiveness in clinical trials (22); however, it has also been associated with education on this subject $(13,23)$, with adequate scientific information being therefore necessary in this regard.

Efforts needed to prevent a disease with around 25,000 new cases annually in Spain (24), and 5-year survival below $50 \%$ (11) seem indisputable. With early detection, survival could be above $90 \%$ (25). Despite evidence supporting screening activities (26), population-based programs have only been implemented in some countries, including France,
United Kingdom, and Finland (7). In Spain 12 out of 17 autonomous communities have pilot projects or already established programs $(19,27)$ where primary care providers are involved. Cooperation by family doctors improves compliance with screening programs in general (28), and with CRC screening in particular $(3,15,29,30)$. Therefore, primary care providers must take part in the design and implementation of these programs, as well as in the development of circuits to ensure a fluent relationship between health care levels $(3,8,14)$. Furthermore, nurses may play a very important role (17) as they devote more time to health care education tasks (7).

To conclude, primary care providers consider screening effective and acceptable for patients, but presently, as screening is only opportunistically performed, the proportion of professionals who recommend it in the mid-risk population is low, particularly in cases with high numbers of assigned population.

\section{ACKNOWLEDGEMENTS}

This study was funded with a grant (Ayuda a la Investigación en Oncología 2010) by "Asociación Española contra el Cáncer" (Junta Provincial de Albacete) (resolution of November 29, 2010).

The authors are grateful for the contributions of all primary care providers in Albacete Health Care District who took part in this study.

\section{Annex. Questionnaire of attitudes towards CRC screening}

In your opinion, is colorectal cancer screening with fecal occult blood testing effective?:

$1 \square$ Very effective $\quad 2 \square$ Quite effective $\quad 3 \square$ Rather ineffective $\quad 4 \square$ Not effective at all $5 \square$ I don't know

In your opinion, the cost-effectiveness of colorectal cancer screening is:

$1 \square$ High $2 \square$ Moderate $3 \square$ Low $4 \square$ I don't know

How do you consider the acceptance of fecal occult blood testing by patients?

$1 \square$ High $2 \square$ Intermediate $3 \square$ Low $4 \square$ I don't know

How do you consider the acceptance of colonoscopy by patients when fecal occult blood is found?

$1 \square$ High $2 \square$ Intermediate $3 \square$ Low $4 \square$ I don't know

Should a population-wide screening program based on fecal occult blood testing (plus colonoscopy when appropriate) become implemented for early colorectal cancer detection in subjects older than 50 years of age, would you recommend it to your patients?

$1 \square$ Yes, to those older than 50 years $2 \square$ Yes, but only in some cases $3 \square$ No $4 \square$ I don't know

Should a population-wide screening program become implemented for early colorectal cancer detection in subjects older than 50 years of age, how do you think their participation would be?

High (over $60 \%$ ) $2 \square$ Intermediate (between 40 and $60 \%$ ) $3 \square$ Low (below $40 \%$ ) $4 \square$ I don't know 


\section{Annex (Cont.). Questionnaire of attitudes towards CRC screening}

Do you consider the cooperation of family doctors significant for the successful development of a colorectal cancer screening program?

$1 \square$ Highly significant $2 \square$ Quite significant $3 \square$ Rather non-significant $4 \square$ Not significant at all

Do you consider the cooperation of nurses significant for the successful development of a colorectal cancer screening program?

$1 \square$ Highly significant $2 \square$ Quite significant $3 \square$ Rather non-significant $4 \square$ Not significant at all

Please score from 0 (not important at all) to 5 (very important) each of the potential barriers for the population to participate in a screening program for colorectal cancer:

Fear to colonoscopy

Lack of knowledge on colorectal cancer

Fear to colorectal cancer identification

Displeasure with fecal sample handling

No perceived benefits from the program

Please score from 0 (not important at all) to 5 (very important) each of the potential barriers for primary care providers to participate in a screening program for colorectal cancer:

The procedure's invasive nature should colonoscopy be required Anxiety problems in patients because of false positive FOBT results False feelings of safety from potential false negative FOBT results Providers' lack of time Difficulty to discuss screening procedures with patients Lack of knowledge of providers on screening programs Lack of knowledge of providers on colorectal cancer Lack of resources for screening implementation

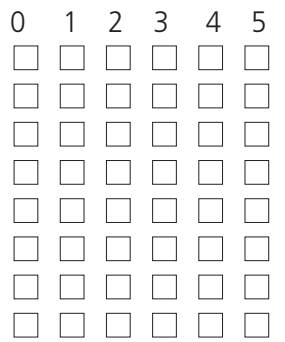

How frequently do you recommend fecal occult blood testing to asymptomatic patients older than 50 years of age?

$1 \square$ Frequently $2 \square$ Sometimes $3 \square$ Never

Do you think you need more knowledge on colorectal cancer screening?

Yes $2 \square$ No

\section{REFERENCES}

1. Estrategia en Cáncer del Sistema Nacional de Salud. Ministerio de Sanidad y Política Social. Plan de Calidad para el Sistema Nacional del Salud. Ministerio de Sanidad, 2010 [consultado 12 junio 2012]. Disponible en: www.msps. es/organizacion/sns/./ActualizacionEstrategiaCancer.pdf

2. Salas D. Cribado del cáncer colorrectal: Fortalezas para avanzar en el cribado en España. Gac Sanit 2011;25:329-30.

3. Marzo-Castillejo M, Mascort Roca J, Pastor Rodríguez-Moñino A. ¿Estamos convencidos de nuestro papel en la prevención y detección precoz del cáncer colorrectal? Aten Primaria 2012;44:303-5.

4. Andreu García M, Marzo M, Mascort J, Quintero E, García-Alfonso P, López-Ibor C, et al. Prevención del cáncer colorrectal. Gastroenterol Hepatol 2009;32:137-9.

5. Pignone M, Rich M, Teutsch SM, Berg AO, Lohr KN. Screening for colorectal cancer in adults at average risk; A summary of the evidence. Ann Intern Med 2002;137:132-41.

6. Bellas Beceiro B, Ferrándiz Santos J, Mascort Roca JJ, Amador Romero FJ, Marzo Castillejo M. Guía de práctica clínica de prevención del cáncer colorrectal: hacia un abordaje integral, integrado y coordinado. Aten Primaria 2004;34:451-3.
7. Ramos M, Esteva M, Almeda J, Cabeza E, Puente D, Saladich R, et al. Knowledge and attitudes of primary health care physicians and nurses with regard to population screening for colorectal cancer in Balearic Islands and Barcelona. BMC Cancer 2010;10:500.

8. Federici A, Rossi PG, Bartolozzi F, Farchi S, Borgia P, Guastcchi G. Survey on colorectal cancer screening knowledge, attitudes, and practices of general practice physicians in Lazio, Italy. Prev Med 2005;41:30-5.

9. Klabunde CN, Frame PS, Meadow A, Jones E, Nadel M, Vernon SW. A national survey of primary care physicians' colorectal cancer screening recommendations and practices. Prev Med 2003;36:352-62.

10. Tong S, Hughes K, Oldenburg B, Del Mar C. Would general practitioners support a population-based colorectal cancer screening program of faecal-occult blood testing? Intern Med J 2004;34:532-8.

11. Damery S, Clifford S, Wilson S. Colorectal cancer screening using the faecal occult blood test (FOBt): A survey of GP attitudes and practices in the UK. BMC Family Practice 2010;11:20.

12. Youl PH, Jackson C, Oldenburg B, Brown C, Dunn J, Aitken J. Attitudes, knowledge and practice of CRC screening among GPs in Queensland. Aust Fam Physician 2006;35:547-50.

13. Rim SH, Zittleman L, Westfall JM, Overholser L, Froshaug D, Coughlin SS. Knowledge, Attitudes, Beliefs, and Personal Practices Regarding 
Colorectal Cancer Screening Among Health Care Professionals in Rural Colorado: A Pilot Survey. J Rural Health 2009;25:303-8.

14. Terhaar sive Droste JS, Heine GDN, Craanen ME, Boot H, Mulder CJJ. On attitudes about colorectal cancer screening among gastrointestinal specialists and general practitioners in The Netherlands. World J Gastroenterol 2006; 12: 5201-4.

15. Turner GB, Chin MW, Foster NM, Emery J, Forbes GM. Attitudes of Western Australian general practitioners to colorectal cancer screening. Med J Aust 2006;185:237.

16. Hilsden RJ, McGregor SE, Murray A, Khoja S. Bryant H. Colorectal cancer screening: Practices and attitudes of gastroenterologists, internists and surgeons. J Can Chir 2005;48:434-40.

17. Shaheen NJ, Crosby MA, O'Malley MS, Murray SC, Sandler RS, Galanko JA, et al. The practices and attitudes of primary care nurse practitioners and physician assistants with respect to colorectal cancer screening. Am J Gastroenterol 2000;95:3259-65.

18. Peris M, Espinàs JA, Muñoz L, Navarro M, Binefa G, Borràs JM, Catalan Colorectal Cancer Screening Pilot Program Group: Lessons learnt from a population-based pilot program for colorectal screening in Catalonia (Spain). J Med Screen 2007;14:81-6.

19. Red de Programas de Cribado de Cáncer. Resultados de los Programas de Prevención de Cáncer Colorrectal, 2012. [Consultado el 18-052013]. Disponible en: http://www.programascancerdemama.org/index. php/situacion-de-los-programas-de-cribado-de-cancer-colorrectal-enespana-ano-2012.

20. Herbert C, Launoy G, Gignoux M. Factors affecting compliance with colorectal cancer screening in France: differences between intention to participate and actual participation. Eur J Cancer Prev 1997;6:4452.
21. Leard LE, Savides TJ, Ganiats TG. Patient preferences for colorectal cancer screening. J Fam Pract 1997;45:211-8.

22. Young J, Ward J, Sladden M: Do the beliefs of Australian GPs about the effectiveness of cancer screening accord with the evidence? J Med Screen 1998;5:67-8.

23. Subramanian S, Klosterman M, Amonkar MM, Hunt TL. Adherence with colorectal cancer screening guidelines: a review. Prev Med 2004;38:536-50.

24. Centro Nacional de Epidemiología: Instituto de Salud Carlos III: la situación del cáncer en España. Madrid: Ministerio de Sanidad y Consumo; 2005.

25. Meyerhardt JA, Mayer RJ. Systemic therapy for colorectal cancer. N Engl J Med 2005;352: 476-87.

26. Hewitson P, Glasziou P, Irwig L, Towler B, Watson E. Screening for colorectal cancer using the faecal occult blood test, Hemoccult. Cochrane Database Syst Rev 2007;1:CD001216.

27. Milà N, García M, Binefa G, Borràs JM, Espinàs JA, Moreno V. Adherencia al programa poblacional de detección precoz de cáncer colorrectal en Cataluña, 2000-2008. Gac Sanit 2012;26:217-22.

28. Ferreira M, Dolan NC, Fitzgibbon ML, Davis TC, Gorby N, Ladewski $\mathrm{L}$, et al. Health care providerdirected intervention to increase colorectal cancer screening among veterans: results of a randomized controlled trial. J Clin Oncol 2005;23:1548-54.

29. Myers RE, Ross EA, Wolf TA, Balshem A, Jepson C, Millner L. Behavioral Interventions to increase adherence in colorectal cancer screening. Med Care 1991;10:1039-50.

30. Zarychanski R, Chen Y, Bernstein CN, Herbert PC. Frequency of colorectal cancer screening and the impact of family physicians on screening behaviour. CMAJ 2007;177:593-7. 